\title{
Hemodynamic and gas exchange effects of inhaled iloprost in patients with COPD and pulmonary hypertension
}

This article was published in the following Dove Press journal:

International Journal of COPD

Number of times this article has been viewed

\author{
Lan Wangl,* \\ Yuan-Zhe Jin ${ }^{2, *}$ \\ Qin-Hua Zhao' \\ Rong Jiang' \\ Wen-hui Wu' \\ Su-Gang Gong' \\ Jing $\mathrm{He}^{\mathrm{l}}$ \\ Jin-Ming Liu' \\ Zhi-Cheng Jing ${ }^{1,3}$ \\ 'Department of Pulmonary \\ Circulation, Shanghai Pulmonary \\ Hospital, Tongji University School \\ of Medicine, Shanghai, China; \\ ${ }^{2}$ Department of Cardiology, The \\ Fourth Affiliated Hospital of China \\ Medical University, Liaoning, China; \\ ${ }^{3}$ Thrombosis and Vascular Medicine \\ Center, State Key Laboratory of \\ Cardiovascular Disease, FuWai \\ Hospital, Peking Union Medical \\ College and Chinese Academy of \\ Medical Sciences, Beijing, China \\ *These authors contributed equally \\ to this work
}

Correspondence: Zhi-Cheng Jing Department of Pulmonary Circulation, Shanghai Pulmonary Hospital, Tongji University School of Medicine, Shanghai 200433, China

Tel $+8602165 I I 5006$

Fax +86 02I 55662767

Email jingzhicheng@vip.163.com
Abstract: Studies have shown that vasodilators such as iloprost can be useful for treating pulmonary hypertension (PH). However, in patients with COPD, vasodilators may inhibit hypoxic pulmonary vasoconstriction and impair gas exchange. The efficacy and safety of iloprost inhalation was assessed in 67 patients with $\mathrm{PH}$ associated with COPD (COPD-PH), diagnosed by right heart catheterization. Of these, 37 patients had severe $\mathrm{PH}$ (mean pulmonary arterial pressure $[\mathrm{mPAP}]>35 \mathrm{mmHg}$ or mPAP $25-35 \mathrm{mmHg}$ with low cardiac index $\left[<2.0 \mathrm{~L} \cdot \mathrm{min}^{-1} \cdot \mathrm{m}^{-2}\right]$ ). All patients received a single $20 \mu \mathrm{g}$ dose of iloprost via a nebulizer ( $4.4 \mu \mathrm{g}$ delivered at the mouthpiece). No serious adverse events were reported. Hemodynamic and gas exchange parameters (arterial blood gas and shunt fraction [Qs/Qt]) were measured or calculated at baseline and $10 \mathrm{~min}$ after iloprost inhalation. mPAP decreased by $2.1 \mathrm{mmHg}(95 \% \mathrm{CI},-3.3$ to -1.0$)$, pulmonary vascular resistance (PVR) decreased by $62.4 \mathrm{dyn} \cdot \mathrm{s} \cdot \mathrm{cm}^{-5}(95 \% \mathrm{CI},-92.9$ to -31.8$)$, and cardiac output increased by $0.4 \mathrm{~L} \cdot \mathrm{min}^{-1}(95 \% \mathrm{CI}, 0.2-0.5)$. There was a more significant decline in PVR in patients with severe COPD-PH than in those with nonsevere COPD-PH. Hypoxemia and intrapulmonary shunt were more extreme in patients with severe COPD-PH. However, there were no significant differences in arterial blood gas and Qs/Qt between patients with nonsevere and severe forms of COPD-PH. In conclusion, iloprost improved pulmonary hemodynamics without detrimental effects on arterial oxygenation in patients with COPD-PH, even in those with severe PH. These findings suggest that the short-term use of iloprost in patients with COPD-PH is effective and well tolerated.

Keywords: iloprost, pulmonary hypertension, COPD pulmonary gas exchange

\section{Introduction}

Pulmonary hypertension $(\mathrm{PH})$ is a serious complication of COPD, present in more than $50 \%$ of patients with severe COPD. ${ }^{1}$ The development of $\mathrm{PH}$ and right heart failure in COPD is associated with a significant reduction in survival. ${ }^{2-4}$ To date, the treatment of $\mathrm{PH}$ in patients with COPD has produced variable and often disappointing results. ${ }^{5}$ Long-term oxygen therapy aimed at correcting hypoxemia is the only treatment proven to slow or reverse disease progression. ${ }^{6}$ Vasodilators reduce pulmonary arterial pressure (PAP), but in COPD they may also worsen arterial oxygenation as a result of greater ventilation-perfusion imbalance, because of the inhibition of hypoxic pulmonary vasoconstriction..$^{7-10}$ Drug administration by inhalation might overcome this problem. Inhalation facilitates access of medications to alveoli; these receive the greatest proportion of air during ventilation; hence, inhaled vasodilators redirect pulmonary blood flow advantageously to these areas while lowering pulmonary pressures. Therefore, the selective properties of inhaled 
vasodilators such as iloprost have potential advantages in the treatment of patients with $\mathrm{PH}$ associated with COPD (COPD-PH). In theory, iloprost could cause pulmonary vasodilation while maintaining gas exchange. Although iloprost was found to be beneficial in a study of patients with PH secondary to interstitial lung disease, ${ }^{11}$ there have been conflicting reports about the effects of iloprost in patients with COPD-PH. ${ }^{10,12}$ Accordingly, the short-term effects of iloprost need to be carefully evaluated in patients with COPD-PH before considering assessment of its long-term efficacy. ${ }^{13}$ The objective of the present study was to assess the acute effects of a single dose of iloprost on pulmonary hemodynamics and gas exchange, and on side effects, in a Chinese population of patients with COPD-PH. We were particularly interested in evaluating the effects of iloprost on gas exchange to analyze the effects of the drug on hypoxic pulmonary vasoconstriction.

\section{Methods}

The study was designed as a prospective, single-center, open-label trial investigating the effect of iloprost inhalation in patients with COPD-PH, and was conducted from October 2008 to November 2013 at the Shanghai Pulmonary Hospital. The study protocol was reviewed and approved by the Ethics Committee of Shanghai Pulmonary Hospital, Tongji University School of Medicine (Shanghai, China). Written informed consent was obtained from all participants before inclusion in the study. The study was conducted in accordance with the ethical principles outlined in the Declaration of Helsinki.

Patients were included in the study if they met the following criteria: 1) COPD was confirmed by pulmonary function test; 2) mean PAP (mPAP) was $\geq 25 \mathrm{mmHg}$, as assessed by right heart catheterization; and 3) COPD management adhered to Global Initiative for Chronic Obstructive Lung Disease (GOLD) guidelines. Patients were excluded if 1) a severe mental disorder prevented appropriate judgment concerning study participation; 2) life expectancy was $<6$ months; 3) COPD was exacerbated within the last 4 weeks or changes in COPD management had occurred within the last 3 months before the start of the study; 4) there were significant signs of left heart failure or pulmonary artery wedge pressure (PAWP) was $>15 \mathrm{mmHg}$; 5) the patient had a history of pulmonary embolism; 6) the cause of PH was not COPD; and 7) the patient was pregnant or breastfeeding. In patients with inadequate COPD management, therapy was optimized according to GOLD guidelines and study inclusion was postponed for 3 months.
PH was classified as severe or nonsevere on the basis of mPAP and cardiac index values. Cardiac index was calculated by dividing cardiac output by body surface area. Patients assigned to the severe $\mathrm{PH}$ group had mPAP $>35 \mathrm{mmHg}$, or $25-35 \mathrm{mmHg}$ in the presence of a low cardiac index $\left(<2.0 \mathrm{~L} \cdot \mathrm{min}^{-1} \cdot \mathrm{m}^{-2}\right)$. Patients in the nonsevere $\mathrm{PH}$ group had mPAP of 25-35 mmHg with a normal cardiac index. ${ }^{14}$

All patients were admitted to an intensive therapy room at the hospital. An 8F introducer sheath (St Jude Medical Inc., MN, USA) was placed in the right internal jugular vein or the right subclavian vein, and a quadric-lumen 7F SwanGanz catheter (Edwards Lifesciences, Irvine, CA, USA) was advanced into the pulmonary artery. Correct positioning of the catheter was verified by chest fluoroscopy. Transducers were positioned at the midaxillary line and zeroed at atmospheric pressure. mPAP, mean systemic arterial pressure, right atrial pressure (RAP), and PAWP were measured at baseline and after vasodilator drug administration. $\mathrm{CO}$ was measured in triplicate using the thermodilution technique (Edwards Lifesciences) with ice-cold isotonic sodium chloride solution. Pulmonary vascular resistance (PVR) was calculated as (mPAP - PAWP)/CO. Cardiac frequency was monitored continuously. Blood for arterial blood gas calculations was taken from the pulmonary and radial arteries. Blood gas tensions were corrected for the patient's body temperature.

The alveolar-arterial oxygen partial pressure difference $\left(\mathrm{D}_{\mathrm{A}}-\mathrm{O}_{\mathrm{a}}\right)$ and pulmonary shunt ratio $(\mathrm{Qs} / \mathrm{Qt})$ were calculated using the following formulae:

$\mathrm{D}_{\mathrm{A}}-\mathrm{a}_{\mathrm{a}} \mathrm{O}_{2}=\mathrm{FiO}_{2} \times 713-(5 / 4) \times \mathrm{PaCO}_{2}-\mathrm{PaO}_{2}\left(\mathrm{FiO}_{2}=\right.$ fraction of inspired oxygen; $\mathrm{PaCO}_{2}=$ partial pressure of carbon dioxide in arterial blood; $\mathrm{PaO}_{2}=$ partial pressure of oxygen in arterial blood); and $\mathrm{Qs} / \mathrm{Qt}=\left(\mathrm{CcO}_{2}-\mathrm{CaO}_{2}\right) /$ $\left(\mathrm{CcO}_{2}-\mathrm{CvO}_{2}\right)\left(\mathrm{CcO}_{2}=\right.$ oxygen content of pulmonary capillary blood; $\mathrm{CaO}_{2}=$ oxygen content of arterial blood; $\mathrm{CvO}_{2}=$ oxygen content of mixed venous blood).

Aerosolized iloprost was jet nebulized (Raindrop ${ }^{\circledR}$ medication nebulizer, Puritan Bennett) with air and delivered via a spacer to the afferent limb of a Y-valve mouthpiece. With $20 \mu \mathrm{g}$ of iloprost added to the nebulization chamber, a dose of $4.4 \mu \mathrm{g}$ was delivered via the mouthpiece using an $\mathrm{LC}^{\circledR}$ Star nebulizer (PARI, Midlothian, VA, USA). The total inhalation time was $10 \mathrm{~min}$. Hemodynamic measurements were made and arterial and central venous blood samples drawn before iloprost inhalation and during the last minute of inhalation, assumed to be the time of peak effect of the drug.

The primary outcome variable was the change in the hemodynamic index. Secondary outcome measures included 
$\mathrm{PaO}_{2}, \mathrm{PaCO}_{2}, \mathrm{Qs} / \mathrm{Qt}$, and $\mathrm{D}_{\mathrm{A}}-\mathrm{O}_{2}$. Comparisons were performed using Student's $t$-test with the Bonferroni correction for multiple comparisons, whereas nonparametric tests (Wilcoxon rank-sum tests) were applied when necessary for data that did not show Gaussian distribution. The correlation of two parameters was assessed using the Pearson correlation coefficient. Mean, median, standard deviation, standard error, and 95\% CI were calculated. A $p$-value of $<0.05$ was considered statistically significant.

\section{Results}

A total of 67 patients ( 40 men, 27 women) were included in the study. Demographic characteristics, echocardiography parameters, and pulmonary function test parameters at baseline are shown in Table 1 as mean values \pm SD. All patients exhibited severe or very severe stages of COPD, showing air trapping with a mean residual volume of $184.7 \% \pm 63.4 \%$, a moderate reduction in carbon monoxide diffusing capacity, and moderate-to-severe hypoxemia. Right heart morphologic changes including either right heart dilation or right hypertrophy were present in all participants. Mean left ventricular ejection fraction was $67.2 \% \pm 9.5 \%$. For 10 patients $(14.9 \%)$, inclusion in the study was postponed while management of their COPD was optimized according to GOLD guidelines. All patients completed the study.

$\mathrm{PH}$ was confirmed in all patients by right heart catheterization at baseline and mean mPAP was $63.1 \pm 23.9 \mathrm{mmHg}$

Table I Characteristics of the patients participating in the study

\begin{tabular}{|c|c|c|c|}
\hline Characteristic & $\begin{array}{l}\text { All patients, } \\
N=67\end{array}$ & $\begin{array}{l}\text { Nonsevere } \\
\text { COPD-PH, } \\
\mathbf{N}=30\end{array}$ & $\begin{array}{l}\text { Severe } \\
\text { COPD-PH, } \\
\mathbf{N}=37\end{array}$ \\
\hline Age, years & $58.3(12.1)$ & $60.7(12.5)$ & $56.3(11.6)$ \\
\hline Men, \% & $40(59.7)$ & $22(73.3)$ & I8 $(48.6)^{*}$ \\
\hline $\mathrm{BMI}, \mathrm{kg} \cdot \mathrm{m}^{-2}$ & $21.3(4.8)$ & $20.8(3.3)$ & $21.7(5.7)$ \\
\hline \multicolumn{4}{|l|}{ Echocardiography } \\
\hline Systolic PAP, mmHg & $63.1(23.9)$ & $47.9(17.0)$ & $74.4(22.0)^{* *}$ \\
\hline LVEF, \% & $67.2(9.5)$ & $64.6(7.7)$ & $69.1(10.3)$ \\
\hline TAPSE, $\mathrm{cm}$ & $17.6(3.2)$ & $18.6(3.0)$ & I7.I (3.2) \\
\hline \multicolumn{4}{|l|}{ Pulmonary function } \\
\hline TLC, $\%$ & $101.7(25.5)$ & $97.1(25.5)$ & $105.2(25.3)$ \\
\hline $\mathrm{FEV}_{1} / \mathrm{FVC}, \%$ & 49.1 (II.I) & $49.3(10.9)$ & 48.9 (II.4) \\
\hline $\mathrm{FEV}_{1}, \%$ & $31.4(13.1)$ & $32.4(12.3)$ & 30.7 (13.7) \\
\hline $\mathrm{RV}, \%$ & I84.7 (63.4) & I73.I (72.5) & $192.9(55.9)$ \\
\hline DLCO/VA, \% & $58.5(3 \mathrm{I} . \mathrm{I})$ & $58.9(3 \mathrm{I} .1)$ & $58.1(32.0)$ \\
\hline
\end{tabular}

Notes: ${ }^{*} p<0.05$ and ${ }^{* *} p<0.01$ compared with values for patients with nonsevere COPD-PH. Data shown are mean (standard deviation) or numbers of patients (men). Abbreviations: BMI, body mass index; COPD-PH, pulmonary hypertension associated with COPD; DLCO/VA, diffusing capacity divided by the alveolar volume; FEV , forced expiratory volume in I second; FVC, forced vital capacity; LVEF, left ventricular ejection fraction; RV, residual volume; systolic PAP, systolic pulmonary arterial pressure; TAPSE, tricuspid annular plane systolic excursion; TLC, total lung capacity. (range 26-65 mmHg). In general, PVR was moderately increased from baseline. Cardiac index was within the normal range in the majority of patients (Table 2). In total, 37 (55.2\%) patients had severe $\mathrm{PH}$ at baseline; the remaining patients had nonsevere $\mathrm{PH}$. Women were in the majority among cases of severe COPD-PH (51.4\%), while there were more men among cases of nonsevere COPD-PH (73.3\%). In patients with severe COPD-PH, mPAP and PVR were much higher at baseline than in those with nonsevere COPD, but there was no significant difference in pulmonary function between the two groups (Table 3).

At baseline, $\mathrm{PaO}_{2}$ was abnormal $(<80 \mathrm{mmHg})$ in all but two patients, and in $56.5 \%$ it was $<60 \mathrm{mmHg}$. $\mathrm{PaCO}_{2}$ was elevated in most patients $(80.6 \%)$, and in $62.7 \%$ of patients it was $>50 \mathrm{mmHg}$. Gas exchange abnormalities were shown by high $\mathrm{D}_{\mathrm{A}}-\mathrm{O}_{\mathrm{a}}$ and Qs/Qt values, compared with normal ranges (Table 2). Severe COPD-PH led to more serious impairment of gas exchange than nonsevere COPD-PH, as a result of lower $\mathrm{PaO}_{2}(p<0.01)$ and greater intrapulmonary shunt $(p<0.05)$. However, there was no significant difference in $\mathrm{PaCO}_{2}$ between the two groups (Table 3).

Overall, inhalation of iloprost produced substantial vasodilation in the pulmonary circulation. Following treatment with iloprost, mPAP decreased by $2.1 \mathrm{mmHg}$ from baseline $(p<0.01)$, increasing cardiac index by $0.2 \mathrm{~L} \cdot \mathrm{min} \cdot \mathrm{m}^{-2}$ $(p<0.01)$ (Table 2$)$. PVR also decreased significantly after iloprost administration (-62.4 dyn $\left.\cdot \mathrm{s} \cdot \mathrm{cm}^{-5}[p<0.01]\right)$. However, no significant effects on systemic circulation were observed (Table 2).

No differences in gas exchange were observed between baseline and after inhalation of iloprost, and there was no trend toward an increase in $\mathrm{PaO}_{2}$ or a decrease in $\mathrm{PaCO}_{2}$ after inhalation. The $\mathrm{D}_{\mathrm{A}}-{ }_{\mathrm{a}} \mathrm{O}_{2}$ and calculated $\mathrm{Qs} / \mathrm{Qt}$ were also maintained following iloprost administration (Table 2). Inhaled iloprost was well tolerated, with no serious adverse events reported by any patients. There was no increase in the severity of dyspnea and only five patients complained of a mild cough.

In addition to the changes in mPAP, cardiac index, and PVR noted in the overall patient population following iloprost treatment, there were interesting differences between the responses observed in patients with severe $\mathrm{PH}$ and those with nonsevere PH. Figure 1 shows mean values \pm SE. In patients with nonsevere COPD-PH, iloprost inhalation did not lead to a significant decrease in mPAP $(30.6 \pm 0.6$ to $29.7 \pm 0.6 \mathrm{mmHg}$ $[p=0.06])$, and there was no significant change in cardiac output (5.4 \pm 0.3 to $5.6 \pm 0.3 \mathrm{~L} \cdot \mathrm{min}^{-1}[p=0.09]$; Figures $1 \mathrm{~A}$ and $\left.\mathrm{B}\right)$. However, there was a significant decline in PVR from 
Table 2 Hemodynamic and gas exchange parameters in patients with COPD-PH before and after administration of iloprost

\begin{tabular}{|c|c|c|c|c|}
\hline Parameter & $\mathbf{N}$ & $\begin{array}{l}\text { Baseline, } \\
\text { mean (SD) }\end{array}$ & $\begin{array}{l}\text { After iloprost, } \\
\text { mean (SD) }\end{array}$ & $\begin{array}{l}\text { Change after iloprost, } \\
\text { mean }(95 \% \mathrm{Cl})\end{array}$ \\
\hline PVR, dyn $\cdot s \cdot \mathrm{cm}^{-5}$ & 67 & $491.9(244.5)$ & $429.6(243.3)^{* *}$ & $-62.4(-92.9$ to -31.8$)$ \\
\hline PAWP, $\mathrm{mmHg}$ & 67 & $10.2(3.5)$ & $10.4(3.6)$ & $0.2(-0.3$ to 0.7$)$ \\
\hline mPAP, mmHg & 67 & $39.6(10.4)$ & $37.4(10.9)^{* *}$ & $-2.1(-3.3$ to -1.0$)$ \\
\hline $\mathrm{RAP}, \mathrm{mmHg}$ & 67 & $7.2(4.4)$ & $7.5(4.6)$ & $0.4(-0.1$ to 0.8$)$ \\
\hline $\mathrm{Cl} x, \mathrm{~L} \cdot \mathrm{min}^{-1} \cdot \mathrm{m}^{-2}$ & 67 & $3.3(0.9)$ & $3.5(0.9)^{* *}$ & $0.2(0.1$ to 0.3$)$ \\
\hline $\mathrm{CO}, \mathrm{L} \cdot \mathrm{min}^{-1}$ & 67 & $5.2(1.7)$ & $5.6(1.9)^{* *}$ & 0.4 (0.2 to 0.5$)$ \\
\hline MAP, mmHg & 67 & $97.0(14.8)$ & $95.1(1.8)$ & $-1.9(-4.3$ to 0.5$)$ \\
\hline $\mathrm{PaO}_{2}, \mathrm{mmHg}$ & 60 & $59.4(11.2)$ & $59.3(11.7)$ & 0.1 (-I.8 to 2.0$)$ \\
\hline $\mathrm{PaCO}_{2}, \mathrm{mmHg}$ & 60 & $5 I .1(12.1)$ & $51.2(13.1)$ & $-0.0 \mathrm{I}(-\mathrm{I} .7$ to $\mathrm{I} .7)$ \\
\hline $\mathrm{SaO}_{2}, \%$ & 60 & $87.5(6.1)$ & $87.2(6.4)$ & $-0.3(-1.4$ to 0.9$)$ \\
\hline $\mathrm{D}_{\mathrm{A}}-{ }_{\mathrm{a}} \mathrm{O}_{2}, \mathrm{mmHg}$ & 60 & $27.5(14.3)$ & $28.6(11.6)$ & I.I (-I.6 to 3.8$)$ \\
\hline Qs/Qt, \% & 60 & $14.9(6.6)$ & $15.6(5.3)$ & 0.7 (-0.5 to 2.0$)$ \\
\hline
\end{tabular}

Note: $* * p<0.01$ compared with pretreatment values.

Abbreviations: $\mathrm{Clx}$, cardiac index; $\mathrm{CO}$, cardiac output; COPD-PH, pulmonary hypertension associated with $\mathrm{COPD}$; $\mathrm{D}_{\mathrm{A}}-\mathrm{O}_{2}$, alveolar-arterial oxygen partial pressure difference; MAP, mean atrial pressure; mPAP, mean pulmonary arterial pressure; $\mathrm{PaCO}_{2}$, partial pressure of carbon dioxide in arterial blood; $\mathrm{PaO}$, partial pressure of oxygen in arterial blood; PAWP, pulmonary arterial wedge pressure; PVR, pulmonary vascular resistance; Qs/Qt, pulmonary shunt ratio; RAP, right atrial pressure; SaO ${ }_{2}$ arterial oxygen saturation.

$317.9 \pm 20.6$ to $290.5 \pm 19.7 \mathrm{dyn} \cdot \mathrm{s} \cdot \mathrm{cm}^{-5}(p=0.02$; Figure $1 \mathrm{C})$. RAP also increased slightly after iloprost administration $(p<0.05)$. No significant effects on systemic blood pressure were observed in patients with nonsevere COPD-PH and arterial blood gas and calculated Qs/Qt were maintained after iloprost inhalation in this group.

In patients with severe COPD-PH, inhaled iloprost caused a decrease in mPAP from $46.8 \pm 1.4$ to $43.7 \pm 1.7 \mathrm{mmHg}(p<0.05$; Figure 1A), and cardiac index increased from $3.2 \pm 0.1$ to
3.5 $\pm 0.2 \mathrm{~L} \cdot \mathrm{min}^{-1} \cdot \mathrm{m}^{-2}(p<0.05$; Table 3$)$. PVR decreased by $89.7 \mathrm{dyn} \cdot \mathrm{s} \cdot \mathrm{cm}^{-5}\left(628.3 \pm 38.5\right.$ to $\left.538.6 \pm 43.6 \mathrm{dyn} \cdot \mathrm{s} \cdot \mathrm{cm}^{-5}\right)$ in patients with severe COPD-PH (Figure 1E). Compared with the $27.4 \mathrm{dyn} \cdot \mathrm{s} \cdot \mathrm{cm}^{-5}$ reduction in PVR in nonsevere cases of COPD-PH, this finding suggests a greater effect of iloprost in patients with severe COPD-PH $(p=0.04)$. The differences between the two groups after inhaled iloprost could also be seen in the change in RAP, which increased in nonsevere COPD-PH but was maintained in severe COPD-PH $(p=0.01)$.

Table 3 Hemodynamic and gas exchange parameters in patients with severe or nonsevere COPD-PH before and after administration of iloprost

\begin{tabular}{|c|c|c|c|c|c|c|}
\hline \multirow[t]{2}{*}{ Parameter } & \multicolumn{3}{|c|}{ Nonsevere COPD-PH } & \multicolumn{3}{|c|}{ Severe COPD-PH } \\
\hline & $\mathbf{n}$ & $\begin{array}{l}\text { Baseline, } \\
\text { mean (SD) }\end{array}$ & $\begin{array}{l}\text { Change after iloprost, } \\
\text { mean }(95 \% \mathrm{Cl})\end{array}$ & $\mathbf{n}$ & $\begin{array}{l}\text { Baseline, } \\
\text { mean (SD) }\end{array}$ & $\begin{array}{l}\text { Change after iloprost, } \\
\text { mean }(95 \% \mathrm{Cl})\end{array}$ \\
\hline PVR, dyn $\cdot s \cdot \mathrm{cm}^{-5}$ & 30 & $317.9(111.3)$ & $-27.4(-49.9 \text { to }-4.8)^{*}$ & 37 & $628.3(234.1)^{* *}$ & $-89.7(-140.7 \text { to }-38.8)^{*, a}$ \\
\hline PAWP, mmHg & 30 & $10.2(2.9)$ & 0.2 (-0.4 to 0.7$)$ & 37 & $9.7(3.7)$ & $0.2(-0.5$ to 1.0$)$ \\
\hline mPAP, $\mathrm{mmHg}$ & 30 & $30.6(3.3)$ & $-1.0(-2.1$ to 0.1$)$ & 37 & $46.8(8.4)^{* *}$ & $-3.1(-5.0 \text { to I.I })^{*}$ \\
\hline $\mathrm{RAP}, \mathrm{mmHg}$ & 30 & $5.6(2.7)$ & $0.8(0.3 \text { to } 1.4)^{*}$ & 37 & $7.4(4.8)$ & $-0.03(-0.7 \text { to } 0.7)^{\mathrm{a}}$ \\
\hline $\mathrm{CO}, \mathrm{L} \cdot \mathrm{min}^{-1}$ & 30 & $5.4(1.7)$ & $0.2(0.1$ to 0.6$)$ & 37 & $5.1(1.7)$ & $0.6(0.3 \text { to } 0.7)^{*}$ \\
\hline $\mathrm{Clx}, \mathrm{L} \cdot \mathrm{min}^{-1} \cdot \mathrm{m}^{-2}$ & 30 & $3.4(0.9)$ & $0.2(0.1$ to 0.6$)$ & 37 & $3.2(0.9)$ & $0.3(0.2 \text { to } 0.4)^{*}$ \\
\hline MAP, $\mathrm{mmHg}$ & 30 & $99.2(16.0)$ & $-1.6(-5.8$ to 3.1$)$ & 37 & $93.9(13.1)$ & $-2.4(-5.0$ to 0.2$)$ \\
\hline $\mathrm{PaO}_{2}, \mathrm{mmHg}$ & 25 & $65.0(11.7)$ & $2.3(-1.4$ to 6.1$)$ & 35 & $55.5(9.4)^{* * *}$ & $-0.9(-3.5$ to 1.8$)$ \\
\hline $\mathrm{PaCO}_{2}, \mathrm{mmHg}$ & 25 & $50.1(9.6)$ & $-0.7(-4.0$ to 2.5$)$ & 35 & $51.9(13.5)$ & $0.8(-1.2$ to 2.8$)$ \\
\hline $\mathrm{SaO}_{2}, \%$ & 25 & $90.5(5.1)$ & 0.01 ( $(-1.13$ to 1.15$)$ & 35 & $85.4(5.9)^{* * *}$ & $-0.5(-2.3$ to 1.3$)$ \\
\hline $\mathrm{D}_{\mathrm{A}}-\mathrm{O}_{\mathrm{a}}, \mathrm{mmHg}$ & 25 & $22.5(10.3)$ & $2.8(-0.9$ to 6.5$)$ & 35 & $31.1(15.6)^{* *}$ & $-0.07(-4.1$ to 3.9$)$ \\
\hline Qs/Qt, \% & 25 & $12.7(5.2)$ & I. $4(-0.4$ to 3.2$)$ & 35 & $16.5(7.0)^{* *}$ & $0.2(-1.5$ to 2.0$)$ \\
\hline
\end{tabular}

Notes: ${ }^{*} p<0.05$ compared with baseline values. ${ }^{* *} p<0.05$ and ${ }^{* * *} p<0.01$ compared with corresponding values for patients with nonsevere COPD-PH. a $p<0.05$ compared with change for patients with nonsevere COPD-PH.

Abbreviations: $\mathrm{Clx}$, cardiac index; $\mathrm{CO}$, cardiac output; COPD-PH, pulmonary hypertension associated with $\mathrm{COPD} ; \mathrm{D}_{\mathrm{A}}-{ }_{\mathrm{a}} \mathrm{O}_{2}$, alveolar-arterial oxygen partial pressure difference; MAP, mean atrial pressure; mPAP, mean pulmonary arterial pressure; $\mathrm{PaCO}_{2}$, partial pressure of carbon dioxide in arterial blood; PaO ${ }_{2}$, partial pressure of oxygen in arterial blood; PAWP, pulmonary arterial wedge pressure; PVR, pulmonary vascular resistance; Qs/Qt, pulmonary shunt ratio; RAP, right atrial pressure; SaO ${ }_{2}$, arterial oxygen saturation. 

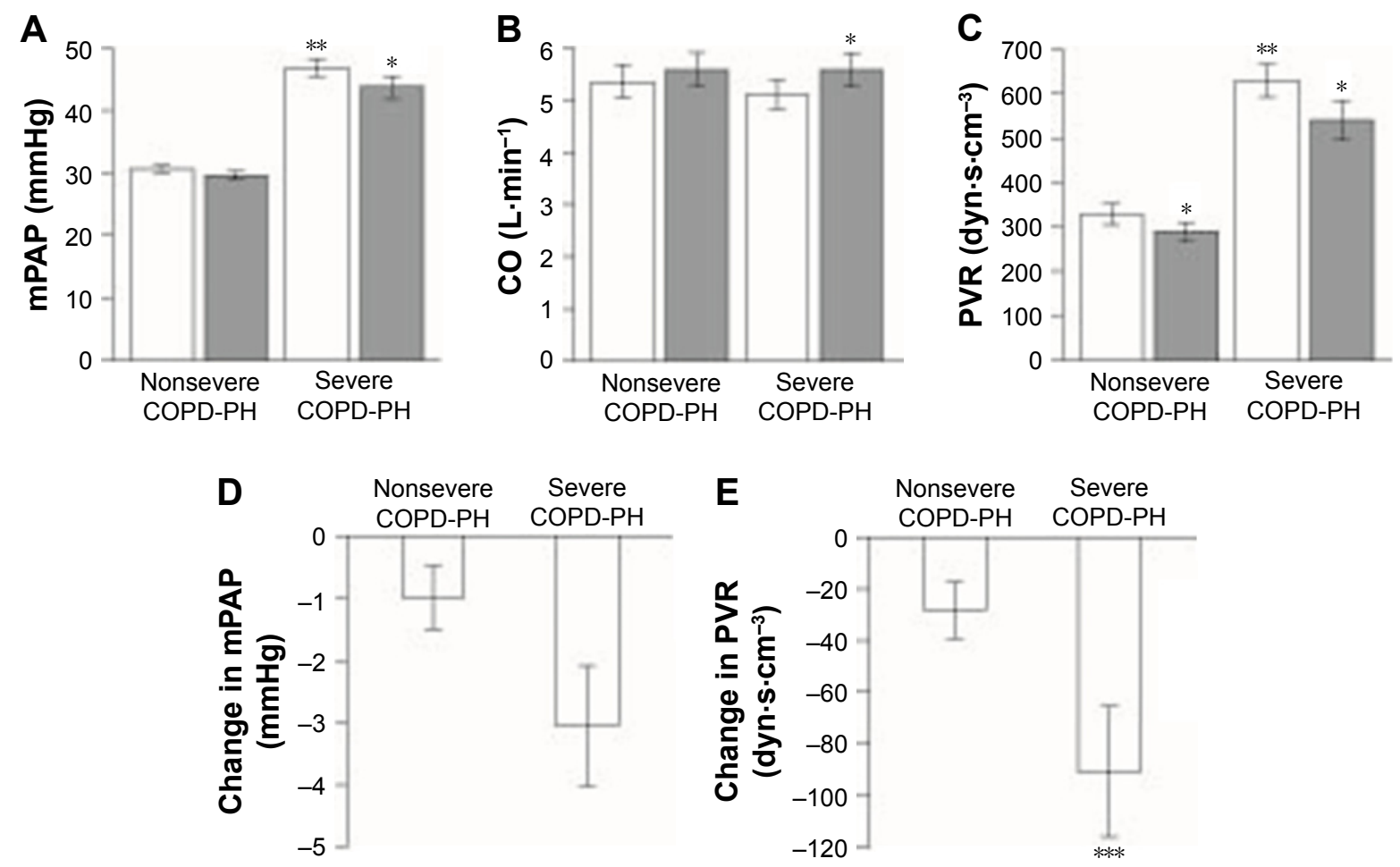

Figure I Effects of iloprost administration on pulmonary hemodynamics.

Notes: Top: for patients with nonsevere and severe COPD-PH, hemodynamic parameters before (open columns) and after (solid columns) iloprost treatment: (A) mPAP, (B) CO, and (C) PVR. Bottom: magnitude of changes induced by iloprost treatment in (D) mPAP and (E) PVR. Values presented as mean \pm standard error. $* p<0.05$ compared with pretreatment values. ${ }^{*} p<0.05$ compared with corresponding values for patients with nonsevere COPD-PH. $* * * p<0.05$ compared with change for patients with nonsevere COPD-PH.

Abbreviations: CO, cardiac output; COPD-PH, pulmonary hypertension associated with COPD; mPAP, mean pulmonary arterial pressure; PVR, pulmonary vascular resistance.

Despite serious hypoxemia in patients with severe COPD-PH, gas exchange did not worsen following iloprost inhalation (Table 3; Figure 2). There were no significant differences between the severe and nonsevere groups in the magnitude of change of $\mathrm{PaO}_{2}, \mathrm{PaCO}_{2}$, arterial oxygen saturation $\left(\mathrm{SaO}_{2}\right), \mathrm{D}_{\mathrm{A}}-{ }_{\mathrm{a}} \mathrm{O}_{2}$, and $\mathrm{Qs} / \mathrm{Qt}$ after iloprost administration.

The most pronounced decrease in $\mathrm{PaO}_{2}$ was experienced by patients with higher values at baseline, as shown by a slight correlation between baseline $\mathrm{PaO}_{2}$ and its decrease after iloprost inhalation in severe COPD-PH ( $\mathrm{r}=-0.55$; Figure $3 \mathrm{~A})$. The similar correlation between baseline $\mathrm{PaO}_{2}$ and increase in $\mathrm{D}_{\mathrm{A}}-{ }_{\mathrm{a}} \mathrm{O}_{2}(\mathrm{r}=0.44)$ and $\mathrm{Qs} / \mathrm{Qt}(\mathrm{r}=0.47)$ was also seen in patients with severe COPD-PH (Figure 3B and C), but not in those with nonsevere COPD-PH.

\section{Discussion}

In recent years, there have been significant improvements in the survival of patients receiving targeted therapies for PH. ${ }^{15}$ Whether specific treatment could also be of benefit in patients with the more prevalent forms of $\mathrm{PH}$, such as that associated with COPD, remains to be determined. ${ }^{13,16}$
However, deleterious effects on gas exchange in patients with COPD ${ }^{12}$ and poor clinical results with vasodilators in patients with COPD-PH suggest that the acute effects of specific therapy should be thoroughly assessed in pilot studies, before evaluating their long-term efficacy. ${ }^{12,17,18}$ Iloprost, a synthetic analog of prostacyclin administered via inhalation, is a selective pulmonary vasodilator that has been shown to improve ventilation-perfusion matching in patients with acute respiratory distress syndrome, ${ }^{19}$ and could offer promise for the treatment of patients with COPD-PH.

In this study, the acute effects of iloprost in patients with COPD-PH were assessed. To the best of our knowledge, this is the first study of iloprost in a Chinese population of patients with COPD-PH and the results presented here complement those of previous studies using vasodilators in patients with COPD.$^{8,13,20}$ Further, there is few evidence for use of iloprost in cases of severe PH with COPD. The effect in severe subgroup of COPD-PH was prominently observed and compared with nonsevere COPD-PH in the study. Our results showed that iloprost inhalation led to a substantial improvement in the pulmonary hemodynamics of patients with COPD and severe or nonsevere PH, while largely 

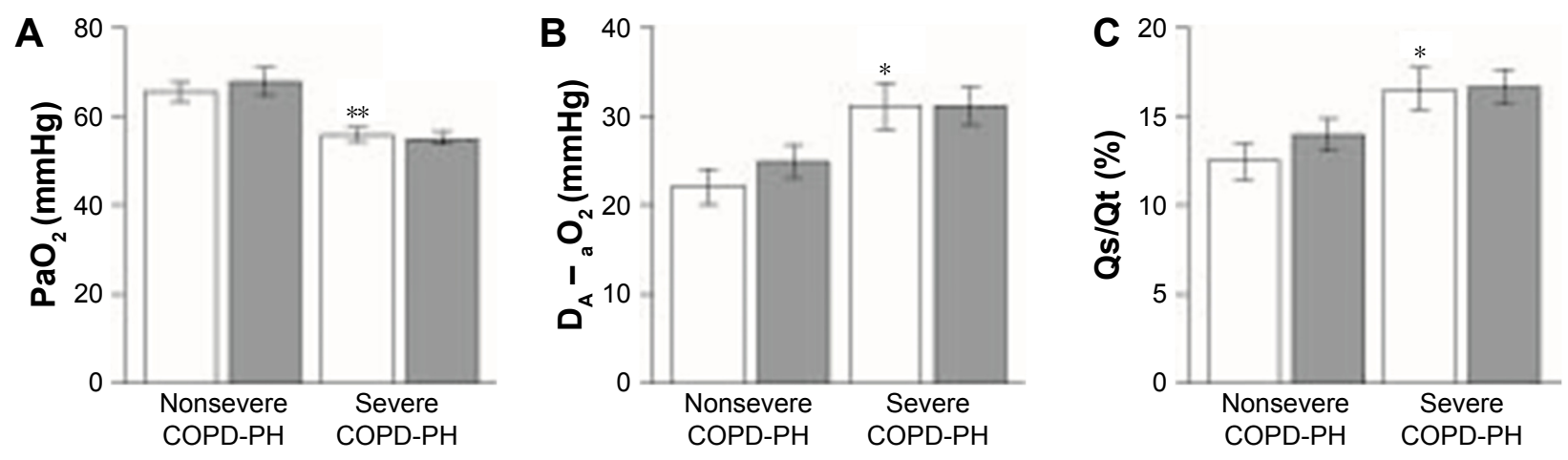

D

E
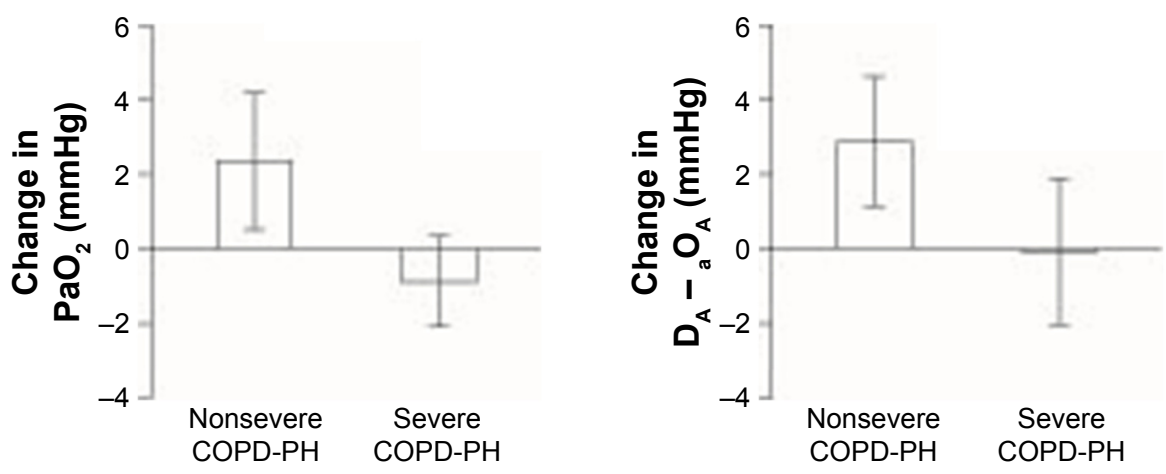

Figure 2 Effects of iloprost administration on gas exchange.

Notes: Top: for patients with nonsevere and severe COPD-PH, gas exchange before (open columns) and after (solid columns) iloprost treatment: $(\mathbf{A}) \mathrm{PaO}_{2}$, $(\mathbf{B}) \mathrm{D}_{\mathrm{A}}-{ }_{\mathrm{a}} \mathrm{O}_{2}$, and (C) Qs/Qt. Bottom: magnitude of changes induced by iloprost administration in (D) $\mathrm{PaO}_{2}$ and $(\mathbf{E}) \mathrm{D}_{\mathrm{A}}-{ }_{\mathrm{a}} \mathrm{O}_{2}$. Values presented as mean \pm standard error. ${ }^{*} \mathrm{p}<0.05$ and $*_{p}<<0.01$ compared with corresponding values for patients with nonsevere COPD-PH.

Abbreviations: COPD-PH, pulmonary hypertension associated with COPD; $\mathrm{D}_{\mathrm{A}}-\mathrm{O}_{\mathrm{a}}$, alveolar-arterial oxygen partial pressure difference; PaO ${ }_{2}$, partial pressure of oxygen in arterial blood; Qs/Qt, pulmonary shunt ratio.

maintaining gas exchange. After iloprost inhalation, mPAP values were reduced in the majority of patients, $\mathrm{CO}$ was increased, and PVR improved. There was no difference in the magnitude of change of oxygenation and intrapulmonary shunt in patients with severe or nonsevere COPD-PH following iloprost inhalation. Interestingly, inhaled iloprost caused a greater decrease in PVR in patients with severe COPD-PH than in those with nonsevere COPD-PH, suggesting that mild hemodynamic impairment in patients with COPD-PH is less sensitive to the beneficial effects of iloprost.

Compared with a study of iloprost in patients with primary $\mathrm{PH}$, the change in acute hemodynamic parameters following iloprost inhalation was less pronounced in patients with COPD-PH. ${ }^{20}$ However, most pulmonary vasodilators
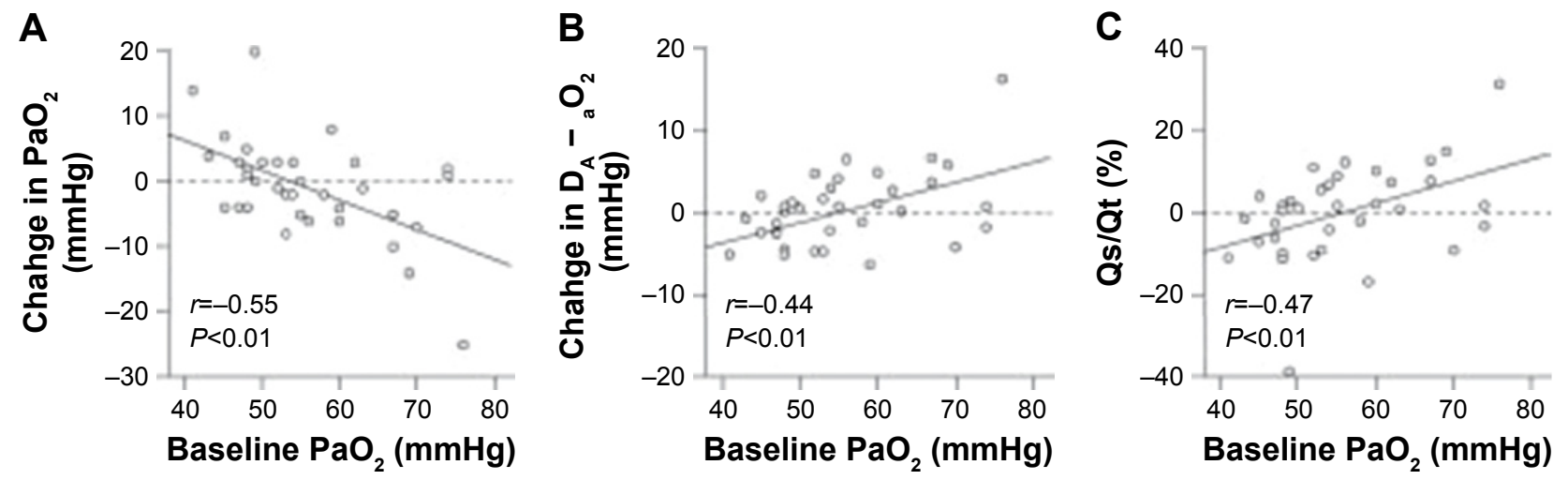

Figure 3 Relationship between baseline $\mathrm{PaO}_{2}$ values and the changes in $(\mathbf{A}) \mathrm{PaO}_{2},(\mathbf{B}) \mathrm{Qs} / \mathrm{Qt}$, and $(\mathbf{C}) \mathrm{D}_{\mathrm{A}}-\mathrm{O}_{2}$ following administration of iloprost to patients with severe COPD-PH.

Abbreviations: COPD-PH, pulmonary hypertension associated with COPD; $\mathrm{D}_{\mathrm{A}}-\mathrm{O}_{2}$, alveolar-arterial oxygen partial pressure difference; PaO ${ }_{2}$, partial pressure of oxygen in arterial blood; Qs/Qt, pulmonary shunt ratio. 
have no efficacy in the treatment of patients with COPD-PH owing to deleterious effects on gas exchange. ${ }^{12,17,21}$ Shortterm administration of sildenafil in patients with COPD-PH improved hemodynamic parameters but led to deterioration in gas exchange. ${ }^{17}$ In a small, randomized, controlled trial of patients with COPD, bosentan therapy failed to improve exercise capacity and resulted in detrimental effects on both gas exchange and quality of life. ${ }^{21}$ Most drugs lack selective vasodilatory properties and consequently inhibit physiologic hypoxic vasoconstriction. With no differences in gas exchange observed following iloprost inhalation, along with no change in $\mathrm{PaO}_{2}$ and $\mathrm{PaCO}_{2}$, our findings indicate unimpaired ventilatory efficiency after iloprost administration in patients with COPD-PH. Although a trend toward an increase in $\mathrm{D}_{\mathrm{A}}-\mathrm{O}_{2}$ and shunting was observed, this was not statistically significant. Our results showed that there was no significant difference in gas exchange between patients with nonsevere and those with severe PH in association with COPD. As suggested in a study of 10 patients in the USA, these findings indicate that targeted delivery of iloprost to ventilated areas is associated with favorable redistribution of blood flow in the lungs of patients with COPD-PH, and avoids the adverse effects associated with the use of systemic vasodilators. ${ }^{10}$ As found with the hemodynamic parameters in patients with COPD, those with greater gas exchange impairment at baseline showed greater improvement after iloprost administration, suggesting that patients with severe COPD-PH might respond better to this therapy than individuals with nonsevere COPD-PH. A recent study found that iloprost reduced peak oxygen consumption and elevated $\mathrm{PaCO}_{2}$ in 16 patients with COPD-PH, ${ }^{12}$ suggesting that iloprost might potentially aggravate air trapping. However, in our study there was no evidence of aggravation of air trapping after iloprost administration.

The major limitation of this study just like other published experiences $^{12,22,23}$ was its short-term design, which restricts findings to only the acute effects of iloprost. In COPD, pulmonary vasodilation without deterioration of gas exchange is challenging caused by the presence of low ventilation/ perfusion ratio areas. ${ }^{24}$ Inhaled iloprost may acutely reduce mPAP and PVR while largely maintaining gas exchange in PH-COPD, especially severe subgroup. However, long-term clinical trials have not been reported. This indicates an urgent need to perform a long-term randomized clinical trial to test whether iloprost should be used as a recommended treatment in severe $\mathrm{PH}$ in patients with COPD. Second, the applied dose of $4.4 \mu \mathrm{g}$ delivered via the mouthpiece using an LC Star nebulizer is not common in other clinical practice. It is hard to make a meaningful comparison with other studies..$^{25,26}$
In addition, cases of severe COPD-PH accounted for over half of the patients in our study. This proportion was much higher than that observed in recent studies of patients with COPD. ${ }^{27}$ It should be noted that our hospital is a pulmonary vascular referral center for patients with $\mathrm{PH}$, so most individuals in this study were seriously ill. Patients with stable COPD and only slightly elevated systolic PAP as estimated by echocardiography declined the right heart catheterization examination.

\section{Conclusion}

Our findings suggest that in patients with COPD-PH, particularly in those with severe PH, iloprost is well tolerated and has favorable effects on acute hemodynamic parameters, without affecting gas exchange. Hence, iloprost may be an improved option for the treatment of patients with severe COPD-PH. However, long-term studies are needed to assess the long-term benefits of iloprost treatment in patients with COPD-PH.

\section{Acknowledgments}

Kathryn Hall, PhD, of Oxford PharmaGenesis, Oxford, UK provided medical writing assistance funded by Bayer HealthCare. Rikesh Sapkota, MD, Ping Yuan, MD, Rui Zhang, MD, and Jin-Ling Li, MD, of Shanghai pulmonary hospital, provided data acquisition.

This study was partly supported by the Project of Shanghai Pulmonary Hospital (fk1416), Program of Shanghai Municipal Health and Family Planning Commission (20164Y0108), the Program of National Natural Science Foundation of China (81600032), and the Yang Fan Program of Shanghai Science and Technology Committee (15YF1409700).

\section{Disclosure}

Dr Jing has relationships with drug companies including Actelion, Bayer Schering, Pfizer, and United Therapeutics, in addition to being an investigator in trials sponsored by these companies; relationships include consultancy services and membership of scientific advisory boards. All the work in this study was completed in the Department of Cardio-Pulmonary Circulation, Shanghai Pulmonary Hospital, Tongji University School of Medicine, Shanghai, China. The other authors report no conflicts of interest in this work.

\section{References}

1. Thabut G, Dauriat G, Stern JB, et al. Pulmonary hemodynamics in advanced COPD candidates for lung volume reduction surgery or lung transplantation. Chest. 2005;127(5):1531-1536.

2. Andersen KH, Iversen M, Kjaergaard J, et al. Prevalence, predictors, and survival in pulmonary hypertension related to end-stage chronic obstructive pulmonary disease. J Heart Lung Transplant. 2012;31(4):373-380. 
3. Cuttica MJ, Kalhan R, Shlobin OA, et al. Categorization and impact of pulmonary hypertension in patients with advanced COPD. Respir Med. 2010;104(12):1877-1882.

4. Shujaat A, Bajwa AA, Cury JD. Pulmonary hypertension secondary to COPD. Pulm Med. 2012;2012:203952.

5. Barbera JA, Peinado VI, Santos S. Pulmonary hypertension in chronic obstructive pulmonary disease. Eur Respir J. 2003;21(5):892-905.

6. Zielinski J, Tobiasz M, Hawrylkiewicz I, Sliwinski P, Palasiewicz G. Effects of long-term oxygen therapy on pulmonary hemodynamics in COPD patients: a 6-year prospective study. Chest. 1998;113(1): 65-70.

7. Agusti AG, Barbera JA, Roca J, Wagner PD, Guitart R, RodriguezRoisin R. Hypoxic pulmonary vasoconstriction and gas exchange during exercise in chronic obstructive pulmonary disease. Chest. 1990;97: 268-275.

8. Barbera JA, Roger N, Roca J, Rovira I, Higenbottam TW, RodriguezRoisin R. Worsening of pulmonary gas exchange with nitric oxide inhalation in chronic obstructive pulmonary disease. Lancet. 1996;347(8999): 436-440.

9. Katayama Y, Higenbottam TW, Diaz de Atauri MJ, et al. Inhaled nitric oxide and arterial oxygen tension in patients with chronic obstructive pulmonary disease and severe pulmonary hypertension. Thorax. 1997:52(2):120-124.

10. Dernaika TA, Beavin M, Kinasewitz GT. Iloprost improves gas exchange and exercise tolerance in patients with pulmonary hypertension and chronic obstructive pulmonary disease. Respiration. 2010; 79(5):377-382.

11. Olschewski H, Ghofrani HA, Walmrath D, et al. Inhaled prostacyclin and iloprost in severe pulmonary hypertension secondary to lung fibrosis. Am J Respir Crit Care Med. 1999;160(2):600-607.

12. Boeck L, Tamm M, Grendelmeier P, Stolz D. Acute effects of aerosolized iloprost in COPD related pulmonary hypertension - a randomized controlled crossover trial. PLoS One. 2012;7(12):e52248.

13. Hoeper MM, Barbera JA, Channick RN, et al. Diagnosis, assessment, and treatment of non-pulmonary arterial hypertension pulmonary hypertension. J Am Coll Cardiol. 2009;54:S85-S96.

14. Seeger W, Adir Y, Barbera JA, et al. Pulmonary hypertension in chronic lung diseases. J Am Coll Cardiol. 2013;62(25 Suppl):D109-D116.

15. Galie N, Manes A, Negro L, Palazzini M, Bacchi-Reggiani ML, Branzi A. A meta-analysis of randomized controlled trials in pulmonary arterial hypertension. Eur Heart J. 2009;30(4):394-403.
16. Hoeper MM. Treating pulmonary hypertension in COPD: where do we start? Eur Respir J. 2008;32(3):541-542.

17. Blanco I, Gimeno E, Munoz PA, et al. Hemodynamic and gas exchange effects of sildenafil in patients with chronic obstructive pulmonary disease and pulmonary hypertension. Am J Respir Crit Care Med. 2010;181(3):270-278.

18. Morrell NW, Higham MA, Phillips PG, Shakur BH, Robinson PJ, Beddoes RJ. Pilot study of losartan for pulmonary hypertension in chronic obstructive pulmonary disease. Respir Res. 2005;6:88.

19. Sawheny E, Ellis AL, Kinasewitz GT. Iloprost improves gas exchange in patients with pulmonary hypertension and ARDS. Chest. 2013;144(1):55-62.

20. Hoeper MM, Olschewski H, Ghofrani HA, et al. A comparison of the acute hemodynamic effects of inhaled nitric oxide and aerosolized iloprost in primary pulmonary hypertension. German PPH study group. J Am Coll Cardiol. 2000;35:176-182.

21. Stolz D, Rasch H, Linka A, et al. A randomised, controlled trial of bosentan in severe COPD. Eur Respir J. 2008;32(3):619-628.

22. Richter MJ, Ghofrani HA, Voswinckel R, et al. Acute hemodynamic effects of nebulized iloprost via the I-neb Adaptive Aerosol Delivery system in pulmonary hypertension. Pulm Circ. 2015;5(1):162-170.

23. Blumberg FC, Riegger GA, Pfeifer M. Hemodynamic effects of aerosolized iloprost in pulmonary hypertension at rest and during exercise. Chest. 2002;121(5):1566-1571

24. Barbera JA, Blanco I. Pulmonary hypertension in patients with chronic obstructive pulmonary disease: advances in pathophysiology and management. Drugs. 2009;69(9):1153-1171.

25. Gessler T, Ghofrani HA, Held M, et al. The safety and pharmacokinetics of rapid iloprost aerosol delivery via the BREELIB nebulizer in pulmonary arterial hypertension. Pulm Circ. 2017;7(2):505-513.

26. Olschewski H, Rohde B, Behr J, et al. Pharmacodynamics and pharmacokinetics of inhaled iloprost, aerosolized by three different devices, in severe pulmonary hypertension. Chest. 2003;124(4):1294-12304.

27. Hoeper MM, Andreas S, Bastian A, et al. Pulmonary hypertension due to chronic lung disease: updated Recommendations of the Cologne Consensus Conference 2011. Int J Cardiol. 2011;154(1 Suppl):S45-S53.
International Journal of COPD

\section{Publish your work in this journal}

The International Journal of COPD is an international, peer-reviewed journal of therapeutics and pharmacology focusing on concise rapid reporting of clinical studies and reviews in COPD. Special focus is given to the pathophysiological processes underlying the disease, intervention programs, patient focused education, and self management protocols.

\section{Dovepress}

This journal is indexed on PubMed Central, MedLine and CAS. The manuscript management system is completely online and includes a very quick and fair peer-review system, which is all easy to use. Visit http://www.dovepress.com/testimonials.php to read real quotes from published authors. 